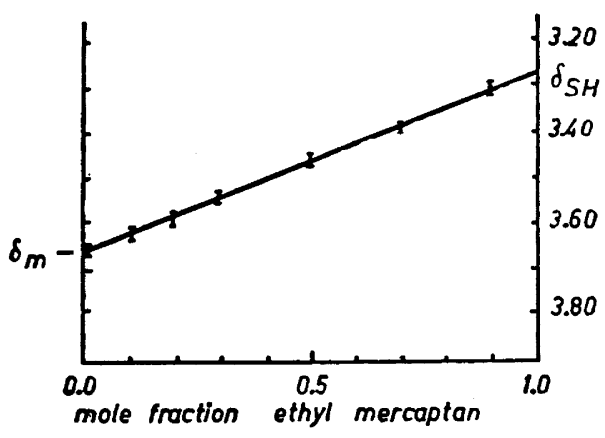

Fig. 2. The dilution shift in $\mathrm{CCl}_{4}$-solution of the SH-proton resonance in terms of the dimensionless unit $\delta$.

The SH-shift shows an almost linear dependence on the mole fraction mercaptan and this behaviour differs markedly from the one observed for alcohols ?. The linear dependence and the smallness of the shift imply that the association constant in terms of mole fractions $\left(K_{x}\right)$ should be small and that monomers and dimers dominate in the solution. Spurr and Byers give $K_{c}=47$ mole/lit., which corresponds to $K_{x}=0.22$. A rather crude approximation based on the formulas in Ref. ${ }^{5 a}$ is to set the slope of the $\delta_{\mathrm{SH}} v s . x$ plot, $\left(\frac{\mathrm{d} \delta}{\mathrm{d} x}\right)$, equal to $2 K_{x} \Delta_{d}$, and, somewhat arbitrarily, $\Delta_{d}=$ $\delta_{d}-\delta_{m}$ to $\frac{1}{2} \cdot 0.38 *$. (See Ref. ${ }^{5 a}$ p. 1313). This gives $K_{x}=0.38$ in reasonable agree. ment with the results of Spurr and Byers.

Acknowledgements. The author would like to thank the head of the NMR group Dr. Erik Forslind for his kind interest in this work. Statens Rad för Atomforskning, Statens Naturvetenskapliga Forskningsrad and Statens Tekniska Forskningsrad have provided financial support. The cost of the NMR apparatus has been defrayed by a generous grant from $K n u t$ och Alice Wallenbergs Stiftelse.

1. Lassettre, E. N. Chem. Rev., 20 (1939) 259.

2. Gordy, W. and Stanford, S. C. J. Am. Chem. Soc. $62(1940) 497$.

* $\delta_{\mathrm{m}}$ is the shift of the monomer in relation to the reference $\left(\mathrm{H}_{2} \mathrm{O}_{\text {ext. }}\right)$ and is given by $\delta \mathrm{sH}$ at $x=0 . \delta_{d}$ is the shift of the dimer and is not known exactly. It can not be taken as the value of $\delta_{\mathrm{SH}}$ at $x=1$.
3. Copley, M. J., Marvel, C. S. and Ginsberg, E. J. Am. Chem. Soc. 61 (1939) 3161.

4. Spurr, R. A. and Byers, H. F. J. Phys. Chem. 62 (1958) 425.

5a. Huggins, C. M., Pimentel, G. C. and Shoolery, J. N. J. Phys. Chem. 60 (1956) 1311.

b. Gutowsky, H. S. and Saika, A. J. Chem. Phys. 21 (1953) 1688.

6. Wilmad Glass Co., Landisville, New Jersey.

7. See e.g. Becker, E. D., Liddel, U. and Shoolery, J. N. J. Mol. Spectr. 2 (1958) 1.

Received September 4, 1959.

\section{Composition and Stability} Constant of the Complex between Lead(II) and 4-(2-Pyridylazo)resorcinol (PAR)

H. KRISTIANSEN and F. J. LANGMYHR

University of Oslo, Chemical Institute $A$, Blindern, Norway

Tor the EDTA-titration of lead(II) Weh4 ber ${ }^{1}$ suggested PAR as metal indicator. Pollard, Hanson and Geary ${ }^{2}$ recommended PAR as colorimetric reagent for cobalt, lead and uranium. The authors introduced $^{3}$ PAR as indicator by indirect EDTAtitration of macro and micro amounts of aluminium, the excess of EDTA being back-titrated with standard lead(II) solution.

In connection with the use of PAR as metal indicator, it is of interest to have information about the complex formed between the indicator and lead(II) ions. In this investigation the composition of the complex and its stability constant were determined spectrophotometrically.

Experimental. The sodium salt of PAR was synthesized according to a procedure given by Chichibabin 4. The salt was purified by extractions with ether and transformed to the phenol by the passing of carbon dioxide. The phenol was extracted with ether, and again transformed to the sodium salt, which was recrystallized from alcohol. The product was finally dried in vacuo over phosphorus pentoxide. The 
disodium salt was not analyzed, but an infrared absorption spectrum confirmed the expected structure.

A solution of PAR in water is orange and showed an absorption maximum at 410 $\mathrm{m} \mu$. In the $\mathrm{pH}$ range 6-10 $\mathrm{PAR}$ and lead(II) form a red complex with an absorption maximum at $515 \mathrm{~m} \mu$. Curves of continuous variations were plotted at $\mathrm{pH} 10$ (ammonia-ammonium chloride buffer) for solutions of PAR and lead(II), and a distinct maximum was obtained at the mole ratio $1: 1$. The curves of continuous variations were then utilized for the calculation of the stability constant, which was found to be $K=3.0 \times 10^{\circ}$. Ionic strength of the solutions was about 0.01 .

1. Wehber, P. Z. anal. Chem. 158 (1957) 10. 2. Pollard, F. H., Hanson, P. and Geary, W. J. Anal. Chim. Acta 20 (1959) 26.

3. Langmyhr, F. J. and Kristiansen, H. Anal. Chim. Acta 20 (1959) 542.

4. Chichibabin, A. E. Zhur. Russ. Fiz.-Khim. Obshchestva 50 (1920) 512.

Received September 7, 1959.

\section{A New Type of Enzymatic Cleavage of Mustard Oil Gluco- sides. Formation of Allylthiocya- nate in Thlaspi arvense $\mathrm{L}$. and Benzylthiocyanate in Lepidium ruderale L. and Lepidium sativum $\mathbf{L}$.}

ROLF GNELIN and ARTTURI I. VIRTANEN

Laboratory of the Foundation for Chemical Research, Biochemical Institute, Helsinki, Finland

\footnotetext{
The cleavage of mustard oil glucosides to isothiocyanate, sulphate, and glucose, which is effected by myrosinase, is considered to be a specific enzymatic process responsible for the characteristic pungent odour or taste of many representatives of the Cruciferae, Tropaeolaceae, Capparid-
}

aceae, Resedaceae, and some other plant families. After having worked out a revised structural formula for the mustard oil glucosides, Ettlinger and Lundeen ${ }^{1}$ proposed that the enzymatic formation of isothiocyanates takes place through Lossenrearrangement (reaction 1). In some other representatives of the Cruciferae family an unpleasant garlic-like odour is characteristic. In the literature there is no real information on the chemical nature and the way of formation of these compounds. Some plant species even derive their names from the garliclike odour (Thlaspi alliaceum L., Alliaria officinalis Andrz., Peltaria alliacea Jacg.).

We have now investigated the chemical nature and formation of the substances that are responsible for this strong garliclike odour, which has led to the use of the term "garlic oils" ("Lauchöle") ${ }^{2}$ in the literature.

With fresh plants and seeds of Thlaspi arvense L., Lepidium ruderale L., and to a somewhat smaller extent of Lepidium sativum L., there appears an unpleasant odour and taste when the plant material is crushed with some water. Our investigations especially with seeds of Thlaspi arvense, Lepidium ruderale, and Lepidium sativum led to the following results:

1. An enzymatic process is responsible for the formation of the unpleasant smelling substances.

2. Sinigrin in Thlaspi arvense and glucotropaeolin in Lepidium ruderale and $L$. sativum are the precursors of the smelling substances.

3. In addition to glucose and sulphate allylthiocyanate in Thlaspi arvense, benzylthiocyanate in Lepidium ruderale, and a mixture of benzylisothiocyanate and benzylthiocyanate in Lepidium sativum are formed as fission products. Synthetic allyland benzylthiocyanates have the same odour and taste as is formed in Thlaspi arvense and Lepidium ruderale. The substances with similar, unpleasant odours, characteristic of many other Cruciferae plants when chewed, are accordingly alkylthiocyanates - a new class of natural $S$. containing compounds. Reactions 1 and 2 illustrate the formation of isothiocyanates and normal thiocyanates.

Experimental evidence for the conclusions:

These smelling substances are not formed when the seedpowder is treated with boiling water or boiling alcohol. In methanolic extracts from seeds of Thlaspi arvense 